\title{
The effect of tactical periodisation on technical effectiveness and intermittent resistance of university tennis players
}

\author{
Diego Polanco Bustos ${ }^{a} \&$ Nelson Mariño Landazábal ${ }^{a}$ \\ ${ }^{a}$ University of Pamplona, Pamplona, Colombia.
}

\section{ABSTRACT}

In tennis, the high demand and unpredictable duration of matches lead us to examine which are the most efficient methodologies for the development of athletes' endurance. The objective of this study was to measure the evolution of technical effectiveness and intermittent endurance in tennis, through the comparison between the tactical periodization method (based on the game) and the ATR (traditional periodisation of accumulation, transformation and realization - based on physical abilities) in university players to establish the difference between methods. 16 university tennis players participated in this study; they were then divided into two groups. Both training methods were applied to each group in a different order, measuring the intermittent resistance after each intervention with an intermittent recovery yo-yo test of level-1 and the specific resistance and technical effectiveness by means of the set-test. The results show that the tactical periodization has a positive effect on the technical effectiveness, achieving a greater number of successful strokes. This occurs without a lower performance in the intermittent resistance, whereas the ATR method achieves a greater ability to travel greater distances in situations decontextualized from the game. The results give insight to physical trainers on how training of resistance could be developed in situations based on the game such as in the tactical periodization method, without neglecting the specific resistance which primarily occurs best in training of isolated physical capacities such as the ATR method.
Key words: specific resistance, tactical periodization, physical training, game-based.

Received: 20 May 2019

Accepted: 28 June 2019

Corresponding author: Diego

Polanco Bustos, Physical

Education, Recreation and

Sports Program, University of Pamplona, Pamplona, Colombia. Email: diegopolco24@hotmail.com

\section{INTRODUCTION}

In a tennis match, power and speed can be seen in every action and a series of these game actions are usually carried out over very short periods of time (Vila, 2014). As a result, it is necessary to develop specific resistance, which in acyclic sports is intermittent for the short bursts of high intensity work and rest (Anselmi, 2012; Baiguet, 2011). Theories of traditional training maintain that the physical conditioning of players could be carried out in the same way as athletes' training (Tamarit \& Frade, 2016). Traditional theories maintain that physical capacities must be trained independently and subsequently these will be transferred to the reality of the game through specific on-court training (Manso, Navarro \& Caballero, 1996; Anselmi, 2012). New theories contradict these theories by assuming that the physical requirements of sports are specific and that physical capacities must be trained and manifested in the reality of the game to achieve an optimal development of fitness (Baiget,
Iglesias \& Rodríguez, 2008; Tamarit \& Frade, 2016; Seirul-lo, 1987). This contradicts the traditional model of training, where the reality of the game is said to be decontextualized. Some authors affirm that it is a loss of energy to train out of context and that energy on the court could be better used in real situations of play with specific cognitive and affective components (Tamarit \& Frade, 2016; Manso et al., 1996). Technical effectiveness is known as the number of successes as a proportion of the total number of executions performed of a sporting skill (Acero, 2013). This technical effectiveness is a factor of utmost importance in the evaluation of the performance of tennis players (Baiget, Iglesias \& Rodríguez, 2008).The proposal of this study is to analyse by means of the ATR and Tactical Periodization methods, the technical effectiveness and the intermittent resistance in university tennis players. 


\section{METHOD}

\section{Participants}

For this study of 16 university players, eleven young male university tennis players aged on average 21.8 years old (S.D.: 2.13), $73.3 \mathrm{~kg}$ (S.D.: 8.52) and $174 \mathrm{~cm}$ tall (S.D.: 0.08), and five female university tennis players aged on average 19.8 years old (S.D.: 2.77), $67.62 \mathrm{~kg}$ (S.D.: 9.29) and $161 \mathrm{~cm}$ tall (S.D.: 0.04 ) were taken as samples and voluntarily agreed to participate in the study. The sample was divided into group 1 and group 2. In order to avoid that the intervention methods and their order had a direct influence on the effects of each intervention, the interventions in the groups were applied in rotation as shown in table 1.

Table 1. Distribution of groups and interventions.

\begin{tabular}{lllll}
\hline & \multicolumn{2}{l}{ First intervention } & \multicolumn{2}{l}{ Second intervention } \\
\hline & method & test & method & test \\
\hline Group 1 & P.T. & Post-test & A.T.R & Post-test \\
\hline Group 2 & A.T.R. & Post-test & P.T. & Post-test \\
\hline
\end{tabular}

Measures and instruments

Measures of resistance and technical effectiveness were taken by means of the following tests:

- $\quad$ The Set-test (Specific Endurance tennis test), was used a ball throwing machine brand tennis 'Tutor Plus Player 3'. The test starts with a throwing frequency of 9 shots/min, increasing periodically to up to 13 shots/min until the exhaustion of the subject. The throwing speed was constant, and the test was carried out in stable environmental and wind conditions. The machine was adjusted so that the ball bounced alternately in the determined zones. Players made alternating forehand and backhand topspin strokes adjusting their speed to the machine rhythm.

An objective evaluation of the technical effectiveness of the subjects was carried out by calculating the percentage of strokes and errors in the stroke, evaluating the precision and power of the strokes by means of lines marked on the court. The hits were successes or errors depending on precision criteria (falling on the target) and power (second bounce after a marked 'power' line). The total number of strokes executed is the sum of the errors and successes during the test. Heart rate was taken at the end of each period by means of the 'Polar H7 bluetooth' and the 'Polar Beat' software.

The test ended when the player could not hit two balls in a row or when at the discretion of the examiner, tennis players did not have to respect a minimum technical model in their strokes.

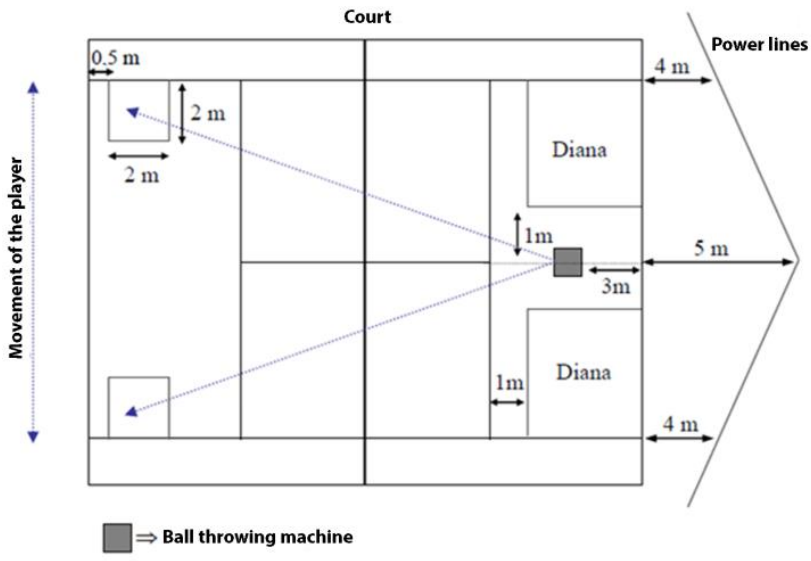

Figure 1. Set-test. Reference. (Baiget, Iglesias \& Rodríguez, 2008) with modifications.

- The yoyo test of intermittent recovery features sprints of $2 \times 20 \mathrm{mts}$ between two markers back and forth. It is a progressive test with a speed increase given by the sound of the recording. Between each sprint there are rest periods of 10 seconds in an area of $2 \times 5 \mathrm{mts}$. When subjects fail to reach the mark twice the test will be finished, the time and distance of completion are recorded. It starts with 4 sprints at $10-13 \mathrm{~km} / \mathrm{h}$ and 7 other sprints from 13.5 to $14 \mathrm{~km} / \mathrm{h}$ followed by a staged increase of $0.5 \mathrm{k} / \mathrm{h}$ until exhaustion. The test was carried out on a uniform terrain (figure 2). Distance travelled and vo2max data were recorded indirectly using the Bangsbo forumla.

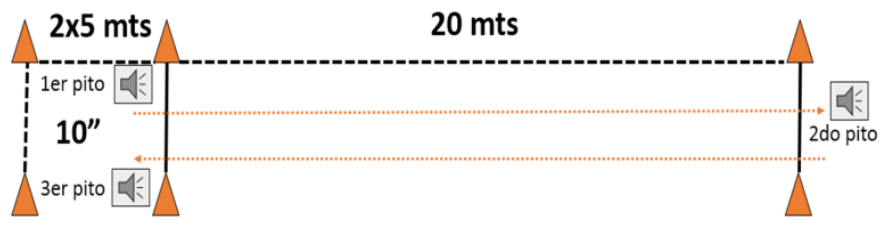

Figure 2. Yo-yo intermittent recuperation test level 1.

\section{INTERVENTION}

We worked for 10 weeks. Each group performed both methods, the duration per intervention was 5 weeks performing 2 sessions per week.

\section{Intervention of the ATR method}

The planning was developed in three stages. The first stage is the accumulation of 3 weeks of working continuous speed sprints; the two following stages consist of a week. The transformation stage consisted of sprints with changes of direction and in the stage of realization, specific closedsituation drills on court were employed. Volume was taken as the number of meters and strokes to be made, and the intensity was taken to be defined by the relationship work rest ratio. An example of a session is: speed sprints of $20 \mathrm{mts} x$ 
9 sets with $13 \mathrm{sec}$. of rest, $15 \mathrm{mts} \times 12$ sets with $10 \mathrm{sec}$. rest and 3 exercises of 48 sets of 4 repetitions of strokes with 25 sec. Rest.

\section{Intervention of the tactical periodization method}

The model of play proposed by the coach were taken into account. Macro-principles and subprinciples were developed to use each day. the principles established are aimed at the overall game. We also take into account that the pattern morphocycle (working week in tactical periodization) includes a day of competition. We replace this day with a day of duration training of muscular contraction (resistance) bearing in mind that this is the day that represents maximum demand and similar characteristics to the competition. The game model was divided into a pro-set format without advantage and a system of direct elimination. From the model were established principles for each phase of the game. In the attacking phase, the following principles were established: controlled aggressiveness and selection of intelligent strokes.

During the neutral phase: striking a power-control balance and using a combination of strokes. Finally during the defensive phase: keeping the ball in play and counterattacking when under pressure. An example of an exercise of the session was: play from the baseline, trying to win the point from the red zone (sub-principle: control of the attack from the baseline). During a 27 minute period, 3 sets of 12 repetitions in which a maximum of 6 strokes have to be executed, resting for 15 -seconds between repetitions.

\section{Analyses of the data}

Descriptive statistics were created for the data. A one-way ANOVA design comparing test parameters was applied for data analysis. In order to test the validity of the models, a study of the data was applied: normality, trends, etc. and a homocedasticity contrast (homogeneity of variances between the groups). The statistical software was SPSS, STATIXTIX 10.0. The level of significance for all tests is $5 \%$.

\section{RESULTS}

Table 2 and Table 3 show the averages, standard deviation and differences at statistical and sports level in each test.

Table 2. Statistic analyse Set-test.

\begin{tabular}{llll}
\hline & SET-TEST & & \\
\hline & T.P & A.T.R. & Differences \\
\hline Success & 44,12 & 30,62 & $\mathrm{P}>0,025$ \\
& $\pm 14,36$ & $\pm 17,88$ & 13,5 golpes \\
\hline Error & 77,06 & 80,31 & $\mathrm{P}<0,612$ \\
& $\pm 17,27$ & $\pm 18,59$ & 3,3 golpes \\
\hline Total strokes & 121,18 & 110,93 & $\mathrm{P}<0,289$ \\
& $\pm 21,58$ & $\pm 31,32$ & 20,2 golpes \\
\hline Technical & 36,33 & 25,98 & $\mathrm{P}>0,002$ \\
effectiveness & $\pm 8,57$ & $\pm 9,23$ & 10,4 golpes \\
\hline Cardiac & 175,77 & 176,32 & $\mathrm{P}<0,763$ \\
frequency & $\pm 4,74$ & $\pm 5,52$ & 1,4 ppm \\
\hline
\end{tabular}

Table 3. Statistic analyse yo-yo test R.I. level 1.

\section{YO-YOTEST R.I.}

\begin{tabular}{llll}
\hline & T.P & A.T.R. & Differences \\
\hline Stade & 13,4 & 13,7 & $\mathrm{P}<0,153$ \\
& $\pm 0,55$ & $\pm 0,67$ & 0,6 \\
\hline Distance & 410,00 & 485,00 & $\mathrm{p}>0,032$ \\
& $\pm 85,79$ & $\pm 103,15$ & $75 \mathrm{mts}$ \\
\hline Vo2max & 39,84 & 40,47 & $\mathrm{p}>0,032$ \\
& $\pm 0,72$ & $\pm 0,86$ & $0,6 \mathrm{ml} / \mathrm{kg} / \mathrm{min}$
\end{tabular}

Figures 3 and 4 show the comparison of the results between methods in the variable technical effectiveness in the set-test and distance in the yo-yo test.

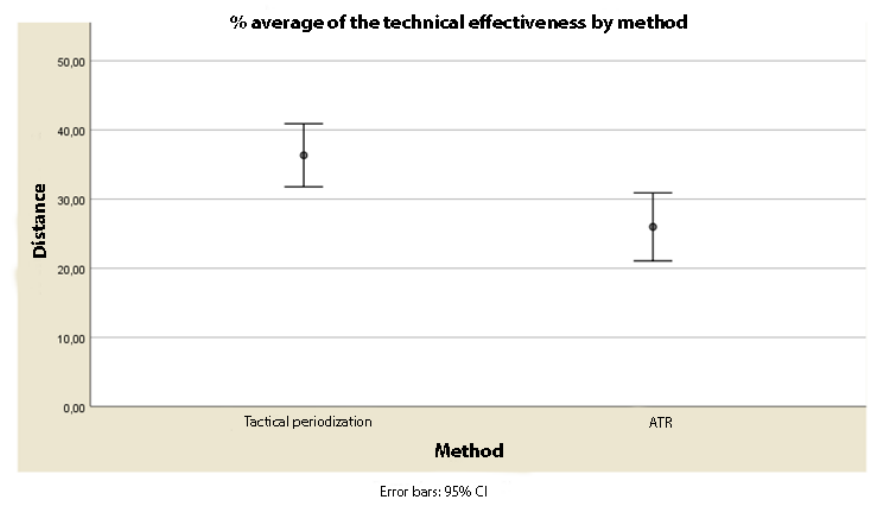

Figure 3. Differences between both tactical periodization and ATR methods for technical effectiveness.

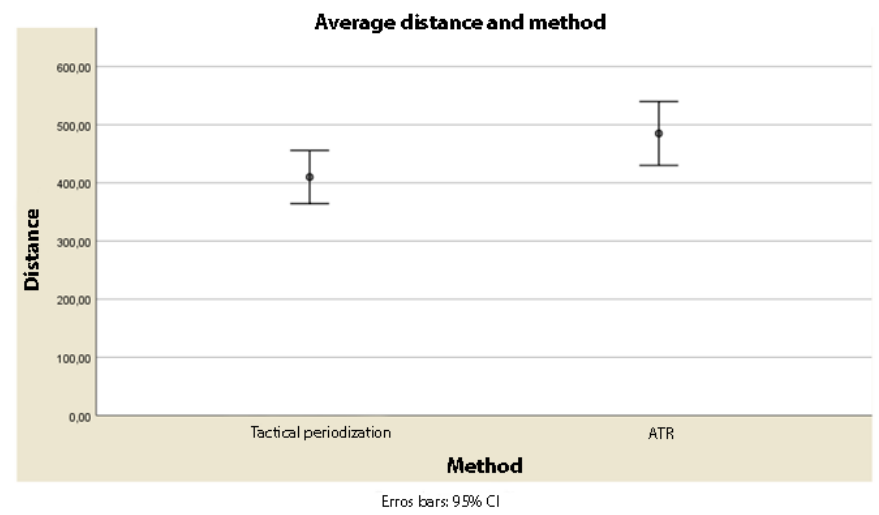

Figure 4. Differences between both tactical periodization and ATR methods for distance.

\section{DISCUSSION}

When we contrast the results obtained from the ATR and tactical periodisation methods we can observe that higher results were obtained in the technical aspects (table 2, figure 3 ) in the tactical periodization model, which implies that it is a method more specific to training on court. The greater 
number of successes in tactical periodization method is reflected in an increase in technical effectiveness. Therefore, this demonstrates that on-court training methods are effective in developing sports performance in tennis in conjunction with improvements in endurance (Srihirun, 2014). This is in line with research in other sports such as football and rugby, that have demonstrated equal development of physical aspects by developing them through play (Hill-Haas, Coutts, Rowsell and Dawson, 2009; Gabbette, 2006).

The results showed similar values in physiological variables as the cardiac frequency. and the vo $2 \max$ (table 2, table 3 ) showing improvements in the assessment of physiological variables in both methods (Fernandez-Fernandez \& cols, 2011; Pialoux \& cols, 2015). We have to mention, that the values of our study are from university players and the levels of university athletes are below those of competitive athletes (Castagna Álvarez and Barbero, 2006). The ATR method obtained the greatest distance travelled (table 3, figure 4); however, when using Bangsbo's calculation (2008) on the yoyo test results to assess the intermittent resistance capacity, we found that healthy active men can run $520 \mathrm{mts}$ with an improvement of $51.9 \mathrm{mts}$ and an elite soccer player can run $873 \mathrm{mts}$ with an improvement of $11 \mathrm{mts}$, this tells us that athletes are at a level of a healthy person. We can analyse that the ATR method has greater advantages in the parameter of distance travelled because a large part of the intervention is similar to the execution of the test, which is reflected in a higher distance covered.

\section{CONCLUSIONS}

The present study shows that there were differences between both methods during the five weeks of intervention. The method of tactical periodization had greater gains with the set-test in terms of technical effectiveness due to a greater number of successful strokes. The ATR method had greater values with the yo-yo test in terms of travelled distance. Both methods are adapted to the development of technical effectiveness and intermittent resistance. The method of tactical periodization offers greater gains in intermittent resistance parameters under decontextualized game conditions. Physical trainers, when performing endurance work on their athletes, can implement tactical-focused training without neglecting the development of the specific endurance in tennis.

\section{REFERENCES}

Acero, J. (2013). Grupo-sobre entrenamiento. Obtenido de http://gse.com/es/biomecanica/wiki/efectividad-de-la-tecnica-deportiva

Anselmi, H. (2012). Cantidad de calidad el arte de la preparación física (5ta ed.). Buenos Aires, argentina: autor-editor.

Baiget, E., Iglesias, X., \& Rodríguez, F. (2008). Prueba de campo específica de valoración de la resistencia en tenis: respuesta cardiaca y efectividad técnica en jugadores de competición. Apuntes edufisica y deporte, 19-28.

Baiget, E. (2011). Metodología de entrenamiento de la resistencia especifica en tenis de competición. Revisión y propuesta. Cultura ciencia y deporte, 45-54, https://doi.org/10.12800/ccd.v6i16.34

Bangsbo, J. f. m. (2008). The Yo-Yo Intermittent Recovery Test A
Useful Tool for Evaluation of Physical Performance in intermitent sports. sports med, 1-15, https://doi.org/10.2165/00007256200838010-00004

Castagna Álvarez, C., \& Barbero, J. C. (2006). el test yo-yo de recuperacion intermitente nivel 1. teknosport, 22-27.

Fernandez-Fernandez, J., Sanz-Rivas, D., Sanchez-Muñoz, C., Tellez, J. G., Buchheit, M., \& Mendez-Villanueva, A. (2011). Physiological responses to on-court vs running interval training in competitive tennis players. Journal of Sports Science and Medicine, 540-545.

Gabbett, T. (2006). Skill-based conditioning games as an alternative to traditional conditioning for rugby league players. Strength \& Conditioning Research, 20 https://doi.org/10.1519/00124278-200605000-00013

Hill-hass, S., Coutts, A., Rowsel, G., \& Dawson, B. (2009). Generic versus small-sided game training in soccer. International Journal of Sport Medicine, 536-642, https://doi.org/10.1055/s-0029-1220730

Manso, J. G., Navarro, M., \& Caballero., J. R. (1996). Planificación del entrenamiento deportivo. Madrid. Madrid: gymnos.

Pialoux, V., Genevois, C., Capoen, A., Forbes, S. C., Thomas, J., \& Rogowski, I. (2015). Playing vs. Nonplaying Aerobic Training in Tennis: Physiological and Performance Outcomes. PLoS ONE, 10(3), https://doi.org/10.1371/journal.pone.0122718

Seirul-lo, F. (1987). La técnica y su entrenamiento. Medicina de lesport, 189-200.

Srihirun, K., Boonrod, W., Mickleborough, T. D., \& Suksom, D. (2014). The Effect of On-Court vs. Off-Court Interval Training on Skilled Tennis Performance and Tolerance to Fatigue in Young Male Tennis Players. American Society of Exercise Physiologists, 11-20, https://doi.org/10.1249/01.mss.0000493952.58661.7e

Tamarit, X., \& Victor, F. (2016). El dia de los macro principios y subprincipios con duración de contracción muscular aumentada. En X. Tamarit, Periodización Táctica VS Periodización Táctica (págs. 97-100). LIBROFÚTBOL.

Vila, C. (2014). Fundamentos prácticos de la preparación física en el tenis (2da ed.). Barcelona: paidotribo.

RECOMMENDED ITF TENNIS ACADEMY CONTENT (CLICK BELOW)

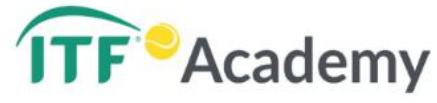

Copyright (c) 2019 Diego Polanco Bustos \& Nelson Mariño Landazábal

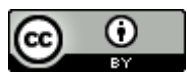

This text is under a Creative Commons BY 4.0 license

You are free to Share - copy and redistribute the material in any medium or format - and Adapt the content - remix, transform, and build upon the material for any purpose, even commercially under the following terms:

Attribution: You must give appropriate credit, provide a link to the license, and indicate if changes were made. You may do so in any reasonable manner, but not in any way that suggests the licensor endorses you or your use.

CCBY 4.0 license terms summary $\quad$ CCBY4.0 license terms 